\title{
Vertical velocity from the Korean GPS Network (2000-2003) and its role in the South Korean neo-tectonics
}

\author{
Ahmed M. Hamdy ${ }^{1,2}$, Pil-Ho Park ${ }^{3}$, and Bong Gon $\mathrm{Jo}^{1}$ \\ ${ }^{1}$ College of Natural Sciences, Basic Science Research Institute Chonbuk National University, Chonju, 561-756, South Korea \\ ${ }^{2}$ Geodynamic Department, National Research Institute of Astronomy and Geophysics, Helwan, Cairo, Egypt \\ ${ }^{3}$ Korea Astronomy Observatory,61-1, Hwaam-dong, Yuseong-gu, Daejeon 305-348, South Korea
}

(Received March 27, 2006; Revised October 22, 2006; Accepted January 10, 2007; Online published June 8, 2007)

\begin{abstract}
In the absence of adequate leveling observations in South Korea, the vertical deformation has been investigated using the Korean Global Positioning System (GPS) Network data (2000-2003). Although the vertical components of the GPS velocities have been rarely used in crustal deformation studies because of their high noise level, the processing strategy employed here enhances the data quality and eliminates the seasonal effect. The obtained vertical velocity field shows that the maximum vertical velocity in the ITRF 97 reference frame is $3.3 \mathrm{~mm} / \mathrm{year}$ (subsidence), which reflects a relatively low level of seismic activity in South Korea. Two deformation patterns were recognized; subsidence in the Okchun Basin, and uplift in its adjacent areas. This subsidence is due to the collision of Kyonggi Massif and Okchun Basin (part of the South China block) against the Yongnam Massif and Taebaeksan Basin (part of the North China block).
\end{abstract}

Key words: KGN, GPS, vertical deformation, Okchun, Korea.

\section{Introduction}

The Korean Peninsula is located between the North and South China Blocks and the Japanese Island Arc as a part of the Eurasian or the Amurian Plate. The Korean Peninsula is standardly categorized into three main blocks of the Archaean and Proterozoic ages (Hurley et al., 1973; Reedman and Um, 1975; Ernst et al., 1988); these are, from north to south, the Nangrim-Pyongnam Massif (PM) and the Kyonggi Massif (KM), separated by the Imjingang Belt (IB) along the western part of the North Korea-South Korea border line, and the Yeongnam Massif (YM), separated from the Kyonggi Massif by the Okchun Belt (OB) (Fig. 1). A number of investigators have suggested that there was a continent-continent collision between the Kyonggi Massif (South China Block) and the Yongnam Massif (North China Block) from the late Permian to the early Triassic (Cluzel et al., 1990, 1991a, b; Cluzel, 1992). Moreover, Chough et al. (2000) has proposed that the Kyonggi Massif (and the Okchun Belt) began to accrete to the Yongnam Massif (and the Taebaeksan Basin), which was located east of the Pyongnam Basin.

The recent tectonic evolution of the Korean Peninsula has been studied by several authors using different geophysical approaches (see Kyung, 1993; Choi et al., 1999; Kim and Lee, 2000). In general, the recent tectonic environment in South Korea (Fig. 1) can be understood by considering two massifs - the Kyonggi Massif and the Yeongnam Massif - and two basins-the Okchun Basin and the Taebaeksan Basin (TB)-separated by five major

Copyright (c) The Society of Geomagnetism and Earth, Planetary and Space Sciences (SGEPSS); The Seismological Society of Japan; The Volcanological Society of Japan; The Geodetic Society of Japan; The Japanese Society for Planetary Sciences; TERRAPUB
faults-Bongwhajae, New-Okchun1, New-Okchun2, Taebkseogchun, and Yangsan.

A program for monitoring the crustal deformation in and around the Korean Peninsula has been designed combining geodetic data, geological structure, seismicity, and tectonic settings (Hamdy and Jo, 2002). In order to carry out the vertical deformation phase of this program, the available geodetic data, those of leveling and GPS, have been studied, since both repeated precise leveling survey data and GPS data provide estimates for the vertical deformation with high precision.

The leveling network in Korea was initially established between 1910 and1915, but all the existing stations in South Korea were virtually destroyed during the Korean War. The Korean National Geographic Information Institute (NGII) reconstructed the Korean first-order leveling network between 1960 and 1986). This network consists of 16 loops and 38 routes with a total length of $3,400 \mathrm{~km}$ and 2,030 benchmarks spaced at intervals of $2-4 \mathrm{~km}$ (Cho, 1999). On the other hand, the Korean GPS Network (KGN), which consists of 50 permanent GPS stations constructed on geologically stable marks (pillars), only became fully operational in 2000. However, since this time, our knowledge on the crustal deformation in the Korean peninsula and its adjacent areas has been improved (Park et al., 2001; Hamdy et al., 2004a, b; 2005).

Mäkinen et al. (2003) claimed that two leveling surveys taken at a 40-year interval would provide accurate vertical velocities of $0.3 \mathrm{~mm} /$ year (by assuming white noise, a precision $\geq 0.8 \mathrm{~mm} / \sqrt{\mathrm{km}}$, and a distance of $100 \mathrm{~km}$ ). They also claimed that 3 years of scattered GPS weekly solutions over the same distance $(100 \mathrm{~km})$ would give similar accuracies. Therefore, in the absence of adequate leveling obser- 


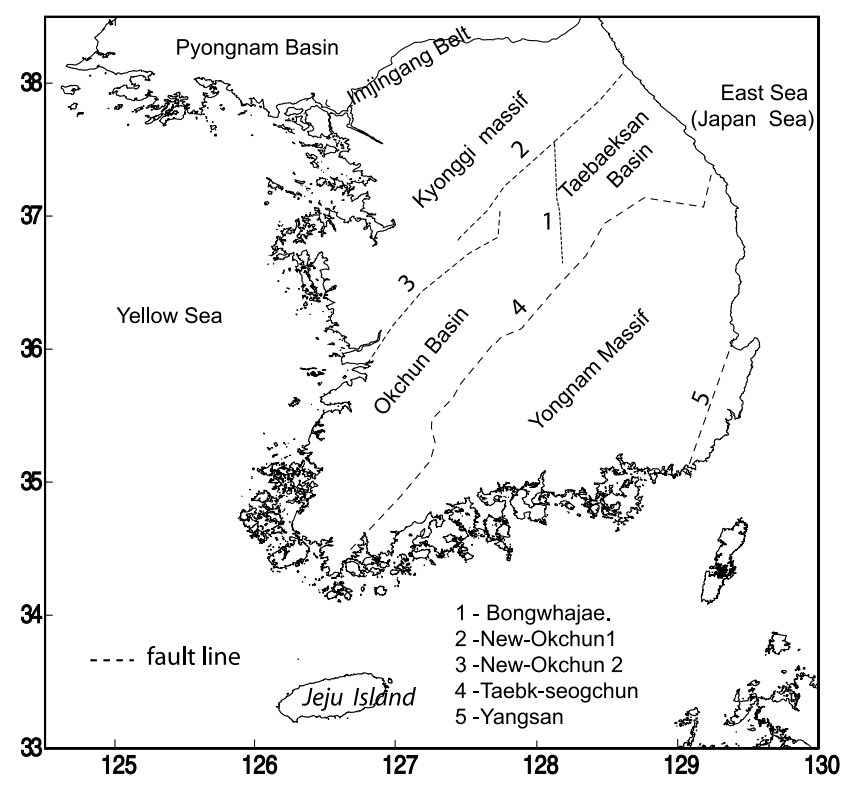

Fig. 1. Map of recent tectonic blocks in South Korea.
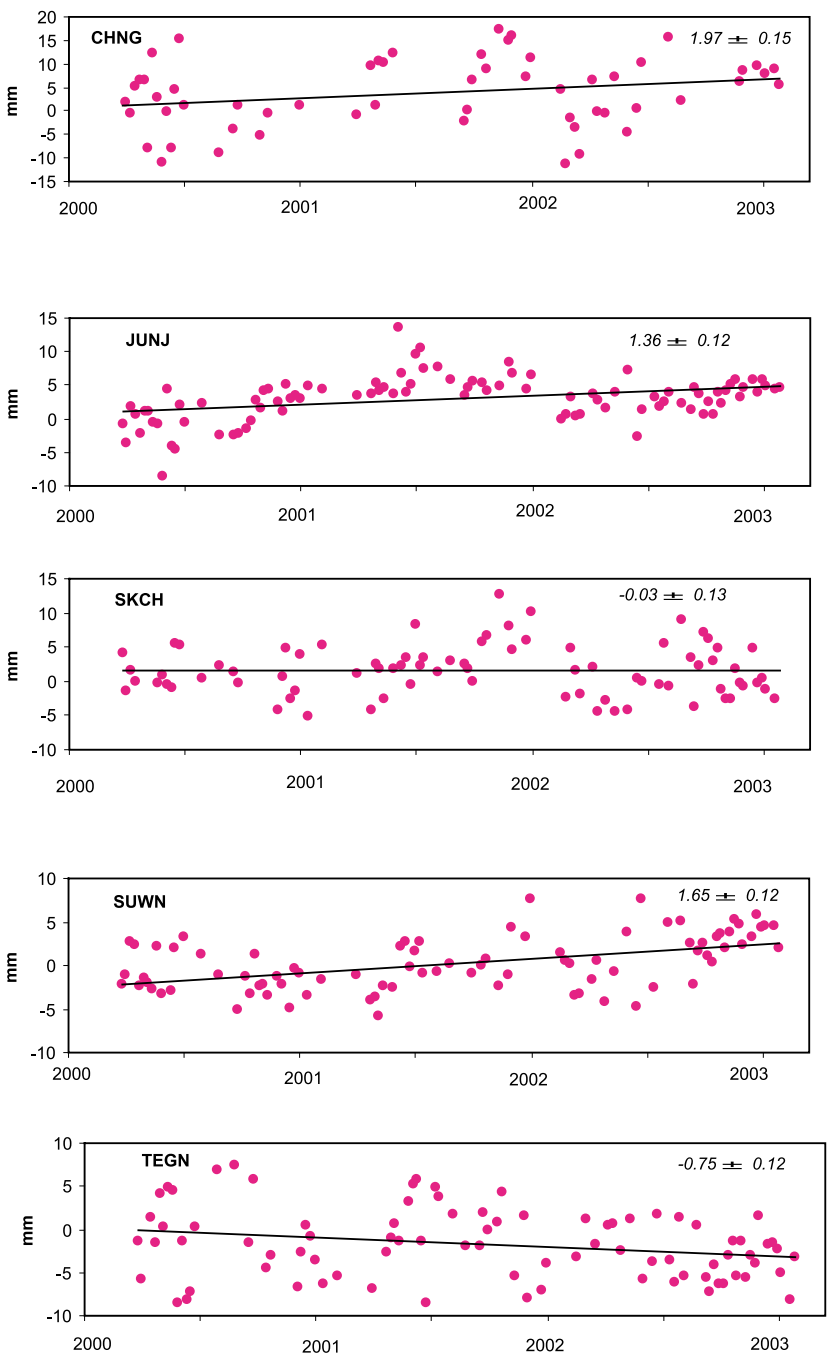

Fig. 2. Time series of the vertical component for selected GPS sites with respect to the DAEJ station. Solid lines are the best fit lines for temporal changes of the vertical component.

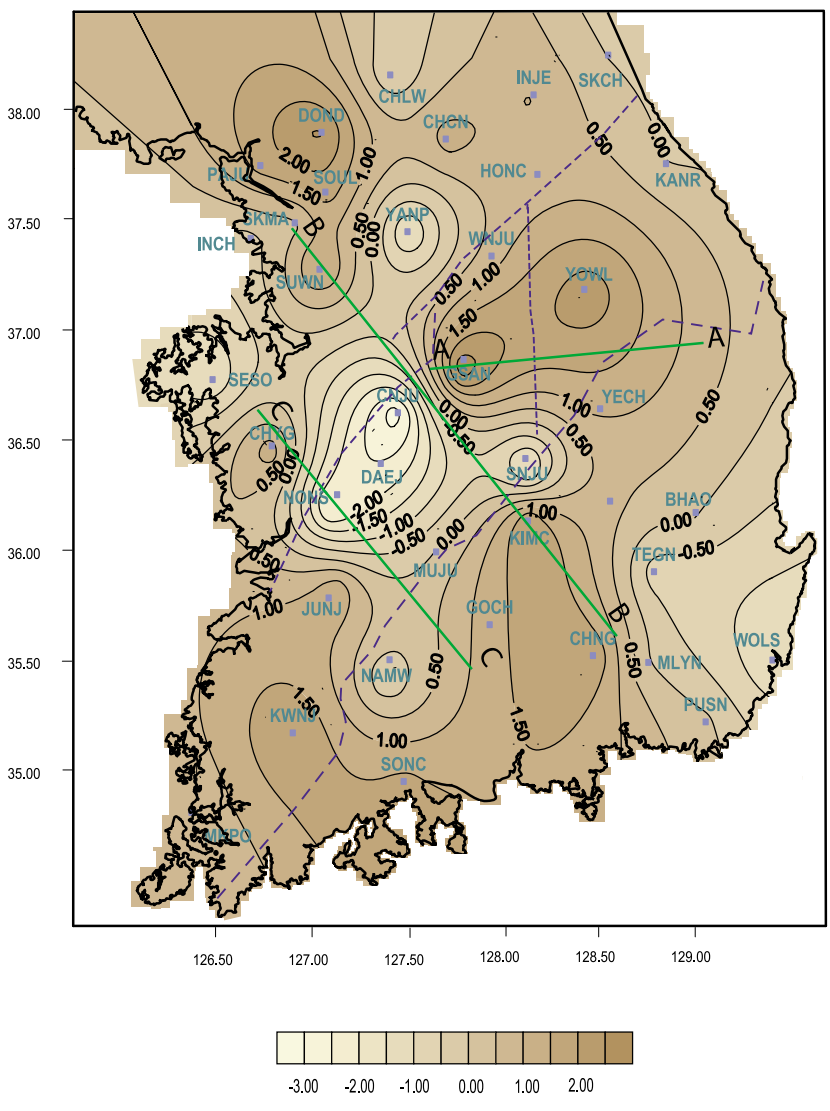

Fig. 3. Contour map with an interval of $0.5 \mathrm{~mm} /$ year representing the vertical movements in South Korea. Dashed lines represent the fault lines, solid lines represent the cross sections shown in Fig. 4.

vations in South Korea, we use the GPS vertical velocities, obtained from the KGN, to investigate vertical movements in the Korean peninsula and their role in the South Korean neo-tectonics.

\section{Data Processing}

The KGN data from April 2000 to March 2003 were processed with the Bernese GPS Software Version 4.2 (Beutler et al., 2001). The International GNSS Service (IGS) final orbits, the satellite clock offsets, the Earth orientation parameters, and the antenna phase center correction models were implemented. Furthermore, the tropospheric delays were estimated using the GPSEST program, and the QIF strategy was employed in the ambiguity resolution. For the daily solutions, the DAEJ station was fixed to the International Terrestrial Reference Frame (ITRF) 97 reference frame, and weekly solutions were generated by combining daily normal equations. Examples of the vertical component time series are presented in Fig. 2.

The seasonal components in the obtained time series (Fig. 2) were eliminated by adopting the following processing strategy: (1) the polar motion, solid earth tide, and ocean tide models were evaluated, and these contributions amounted to up to $66 \%$ of the seasonal effect (Dong et al., 2002); (2) the indirect sources coming from mixed receiver types were eliminated since all the KGN stations use the same type of receiver, Trimble $4000 \mathrm{SSi}$; (3) the used ad- 

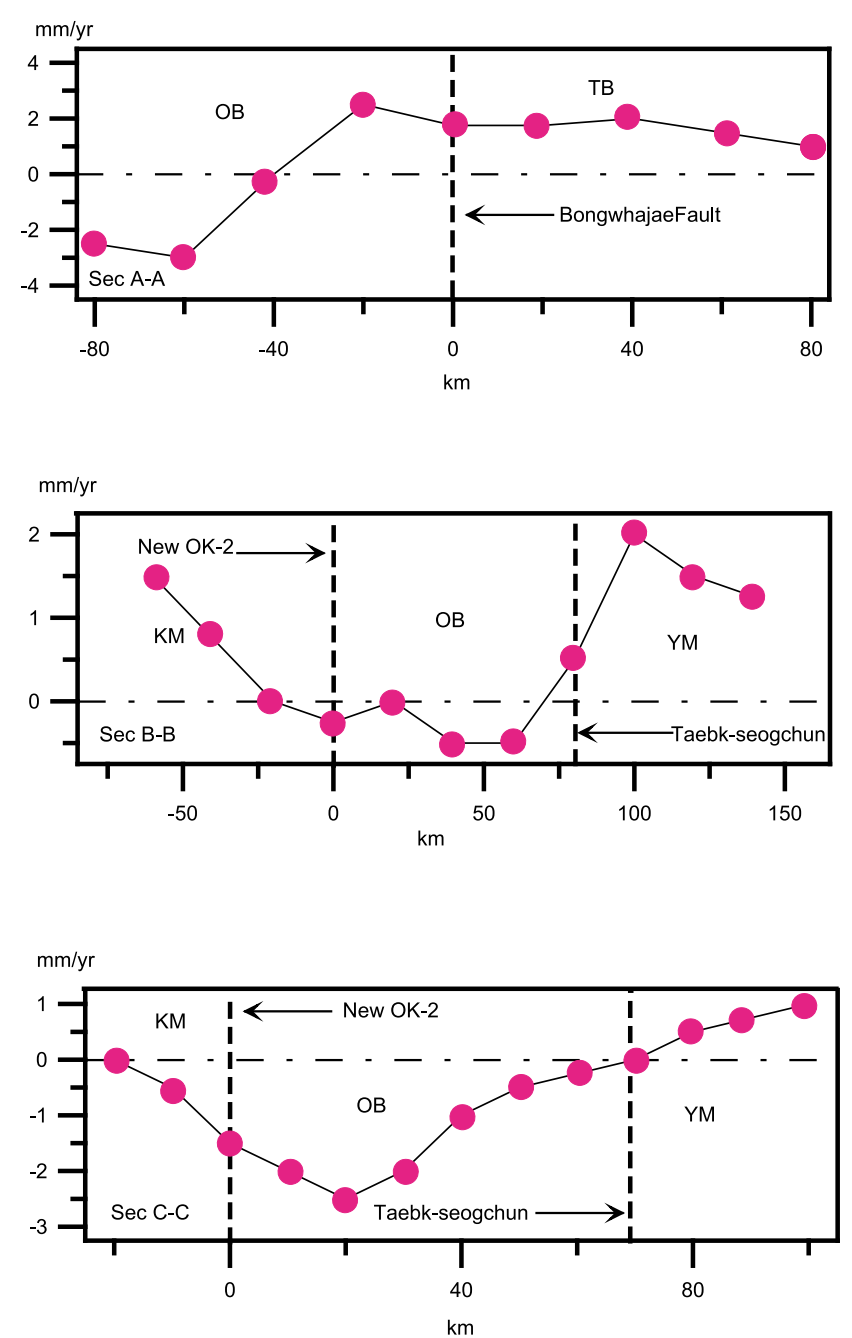

Fig. 4. Vertical velocities along the cross sections shown in Fig. 3. Vertical dashed lines represent the locations of the faults.

justment strategy (fixed network adjustment), together with the small size of the KGN (400 km long and $200 \mathrm{~km}$ wide) eliminate other sources of seasonal effect.

It is noteworthy that there is no evidence of shifts in levels, changes in the trends, and/or jumps in the given time series since none of the KGN stations antennas were replaced during the operational period. Finally, eight stations have been excluded from this study either for not covering the considered period or for showing abnormally large error ellipses in the station position

\section{Results and Discussion}

The estimated vertical velocity field in South Korea shows that the maximum subsidence $(-3.3 \mathrm{~mm} / \mathrm{year})$ is at the CNJU station, while the maximum uplift ( $2.9 \mathrm{~mm} / \mathrm{year})$ is at the GSAN station (Table 1). The vertical velocities in Korea are much less than those in the Japanese Islands, where the largest velocity amounts to $8 \mathrm{~mm} /$ year (Aoki and Scholz, 2003). This difference reflects the lower level of seismic activity in South Korea and its higher tectonic stability.

Using the GPS vertical velocity results (Table 1), we have drawn up a contour map with an interval of $0.5 \mathrm{~mm} / \mathrm{year}$
Table 1. Vertical velocities (normal to ITRF97 surface) in the KGN stations from April 2000 to March 2003 with respect to the DAEJ station and their RMS.

\begin{tabular}{|c|c|c|c|c|}
\hline Station & $\mathrm{E}$ & $\mathrm{N}$ & Vertical & RMS \\
\hline BHAO & 128.98 & 36.16 & 0.08 & 0.21 \\
\hline $\mathrm{CHCN}$ & 127.71 & 37.87 & 1.23 & 0.14 \\
\hline CHLW & 127.42 & 38.16 & -0.49 & 0.14 \\
\hline CHNG & 128.48 & 35.53 & 1.97 & 0.15 \\
\hline CHYG & 126.8 & 36.46 & 1.34 & 0.14 \\
\hline $\mathrm{CNJU}$ & 127.46 & 36.63 & -3.30 & 0.18 \\
\hline DAEJ & \multicolumn{4}{|c|}{ Fixed Station } \\
\hline DOND & 127.06 & 37.9 & 2.62 & 0.14 \\
\hline GOCH & 127.94 & 35.67 & 1.27 & 0.14 \\
\hline GSAN & 127.79 & 36.82 & 2.9 & 0.13 \\
\hline HONC & 128.19 & 37.71 & 0.67 & 0.14 \\
\hline INCH & 126.69 & 37.42 & -0.14 & 0.14 \\
\hline INJE & 128.17 & 38.07 & 1.03 & 0.14 \\
\hline JUNJ & 127.14 & 35.84 & 1.36 & 0.12 \\
\hline KANR & 128.87 & 37.77 & -0.02 & 0.17 \\
\hline KIMC & 128.14 & 36.14 & 2 & 0.23 \\
\hline KUNW & 128.57 & 36.23 & 0.67 & 0.14 \\
\hline KWNJ & 126.91 & 35.18 & 2.01 & 0.2 \\
\hline MKPO & 126.38 & 34.82 & 0.45 & 0.16 \\
\hline MLYN & 128.74 & 35.49 & 0.12 & 0.28 \\
\hline MUJU & 127.66 & 36 & 0.03 & 0.16 \\
\hline NAMW & 127.4 & 35.42 & -0.44 & 0.15 \\
\hline NONS & 127.1 & 36.19 & -2.61 & 0.16 \\
\hline PAJU & 126.74 & 37.75 & 1.71 & 0.15 \\
\hline PUSN & 129.07 & 35.23 & 0.12 & 0.14 \\
\hline SESO & 126.49 & 36.78 & -1.47 & 0.16 \\
\hline SKCH & 128.56 & 38.25 & -0.03 & 0.13 \\
\hline SKMA & 126.92 & 37.49 & 0.35 & 0.23 \\
\hline SNJU & 128.14 & 36.38 & -1.75 & 0.2 \\
\hline SONC & 127.49 & 34.96 & 1.63 & 0.2 \\
\hline SOUL & 127.08 & 37.63 & 1.78 & 0.11 \\
\hline SUWN & 127.05 & 37.28 & 1.65 & 0.12 \\
\hline TEGN & 128.8 & 35.91 & -0.75 & 0.12 \\
\hline WNJU & 127.95 & 37.34 & 0.74 & 0.14 \\
\hline WOLS & 129.42 & 35.51 & -1.44 & 0.15 \\
\hline YANP & 127.51 & 37.45 & -1.58 & 0.16 \\
\hline YECH & 128.45 & 36.65 & 1.09 & 1.2 \\
\hline YOWL & 128.46 & 37.18 & 2.33 & 0.17 \\
\hline
\end{tabular}

(Fig. 3). Apart from the edge effect, the contour map shows two primary deformation patterns: subsidence in the center of $\mathrm{OB}$ and an uplift of the surrounding region. Several cross sections (Fig. 4) in the contact area between the two juxtaposed blocks (KM-OB and YM-TB) were investigated. The first cross section (section A-A in Fig. 4) is perpendicular to the Bongwhajae fault line and shows that the TB stations were uplifted while those of OB subsided. This deformation pattern can be explained by considering the horizontal strain tensor observed during the same period 2000-2003, in $\mathrm{OB}$ where the predominant strain was compression and the basin translates toward SW (Hamdy et al., 2005).

The second cross section along the northern part of OB (section B-B in Fig. 4) demonstrated that the KM and YM stations uplifted while those in OB mostly subsided. Taking account of the hypothesis of continent-continent collision (Cluzel et al., 1990, 1991a, b ; Cluzel, 1992; Chough et al., 2000) and the horizontal deformation tensors presented 

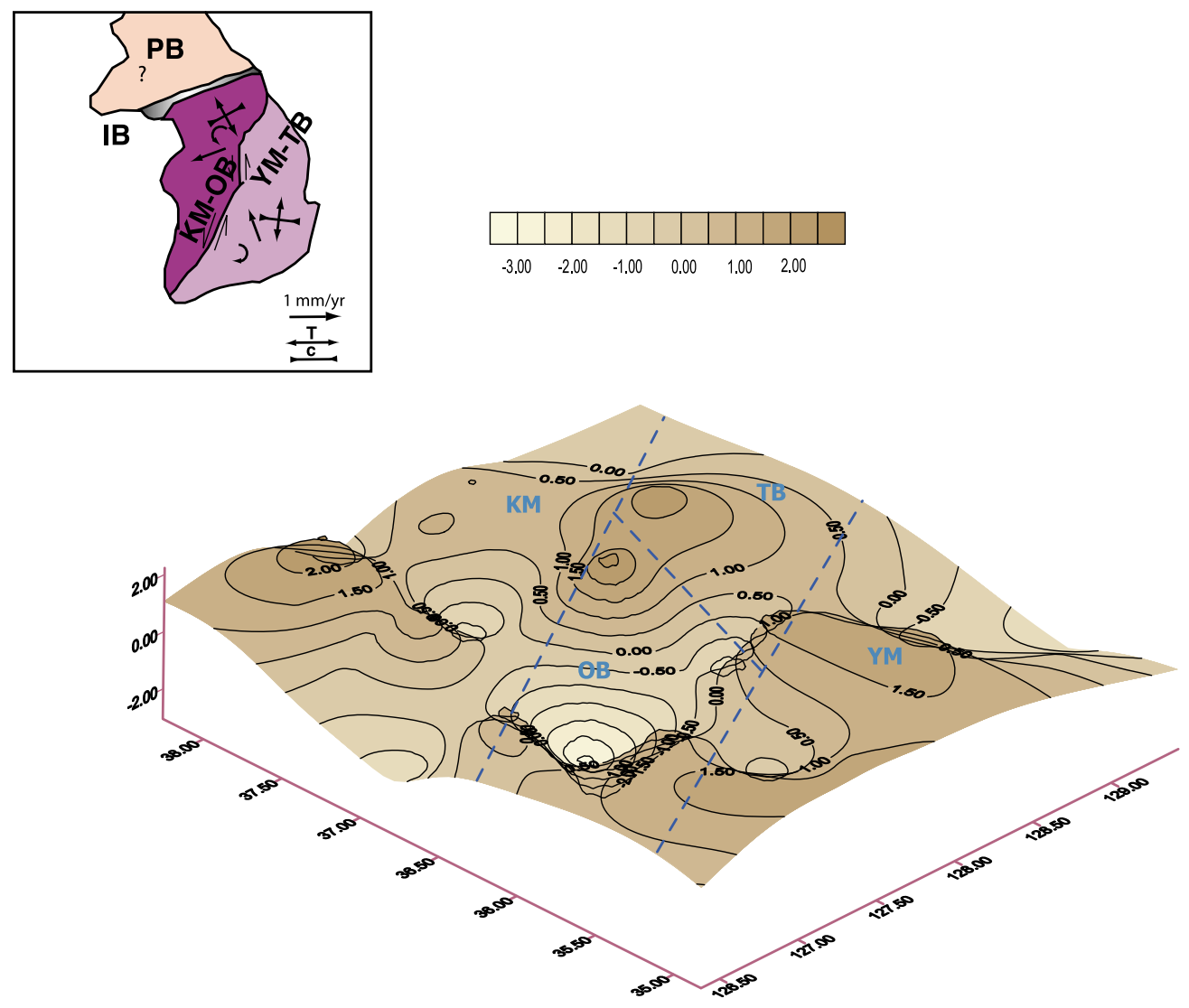

Fig. 5. Surface map showing the vertical velocities in South Korea. Dashed lines represent the fault lines. The inset map shows the horizontal deformation tensors after Hamdy et al. (2005).

by Hamdy et al. (2005), where YM-TB translates toward the NWN with clockwise rotation and KM-OB translates toward WSW with anticlockwise rotation, the combination of these strain tensors is considered to result in compression in the contact zone and its surroundings and the subsidence pattern of $\mathrm{OB}$.

The third cross section (section C-C in Fig. 4) is located in the central part of $\mathrm{OB}$ and is almost parallel to the section B-B. This section, as well as the previous two sections, suggests the presence of a subsidence pattern in OB. In addition, it shows that the subsidence in the central part of $\mathrm{OB}$ is larger than that in the northern part.

In general, a combination of subsidence (this study) and contraction (Hamdy et al., 2005) are clearly found in OB (Fig. 5). The subsidence of $\mathrm{OB}$ can be explained as the downwarping of the basement due to the horizontal stress regime surrounding it, due to the collision of KM-OB (part of the South China block) against YM-TB (part of the North China block). This proposal may be justified by considering the negative gravity anomaly found to the south of Taejon (Choi et al., 1999), possibly caused by the downwarping of the basement and consequent crustal thickening. Moreover, it is worth pointing out that the observed subsidence in OB is composed of two main parts - the sediment compaction and the actual subsidence. In order to distinguish the actual subsidence, we need to have better information on the geological structure of OB that helps us determine the compaction part and then obtain the accurate subsidence movement.

\section{Conclusion}

We derived the distribution of the vertical deformation field in South Korea from continuous GPS data during the period 2000-2003. The maximum velocity was 3.3 $\mathrm{mm} /$ year (subsidence), and this result reflects the stability of South Korea and the lower level of seismic activity there. Two primary deformation patterns were found in South Korea: fast subsidence in the central part of the Okchun Basin and uplift of the surrounding area. The horizontal strain tensors and the subsidence of the Okchun Basin are due to the collision of the Kyonggi Massif and the Okchun Basin against the Yongnam Massif and the Taebaeksan Basin. More comprehensive results would be achieved using a larger GPS data set (longer time span and more stations along the eastern coast), and detailed studies of structural geology in South Korea (the Okchun Basin) would be beneficial.

Acknowledgments. The authors thank the Ministry of Government Administration and Home Affairs, National Geographic Information Institute of Korea, for their data contribution and also KIGAM are acknowledged for the fault line data. The critical review of Dr. Yosuke Aoki and Dr. Satoshi Miura, together with the kind support and advice of Prof. Dr. Kosuke Heki, much improved the manuscript. The Chonbuk National University is acknowledged for supporting the first author via the 2005 post-doctoral program.

\section{References}

Aoki, Y. and C. H. Scholz, Vertical deformation of the Japanese islands, 1996-1999, J. Geophys. Res., 108(B10), 2470, doi:10.1029/ 
2003JB002441, 2003.

Beutler, G. F., et al., Bernese GPS software Version 4.2, Astronomical institute, University of Bern, 2001.

Cho, H., Grids and Datum the Republic of Korea, J. Am. Soc. Photogrammetry Remote Sensing, 65, 11, 1243-1247, 1999.

Choi, K. S., G. V. R. Kumar, and K. Y. Kim, Qualitative interpretation of Bouguer anomaly in the south part of the Korean peninsula, Geosci. J., 3, 1, 49-54, 1999.

Chough, S. K., S. T. Kwon, J.-H. Ree, and D. K. Choi, Tectonic and sedimentary evolution of the Korean peninsula: review and new view, J. Earth Sci. Rev., 52, 175-235, 2000.

Cluzel, D., Late Paleozoic to early Mesozoic geodynamic evolution of the circum-Pacific orogenic belt in South Korea and Southwest Japan, Earth Planet Sci. Lett., 108, 289-306, 1992.

Cluzel, D., J.-P. Cadet, and H. Lapierre, Geodynamics of the Ogcheon Belt (South Korea), Tectonophysics, 183, 41-56, 1990.

Cluzel, D., B. J. Lee, and J. P. Cadet, Indosinian dextral ductile fault system and synkinematic plutonism in the southwest of the Ogcheon belt South Korea, Tectonophysics, 194, 131-151, 1991a.

Cluzel, D., L. Jolivet, and J.-P. Cadet, Early middle Paleozoic intraplate orogeny in the Ogcheon belt South Korea: a new insight on the Paleozoic buildup of east Asia, Tectonics, 10, 1130-1151, $1991 \mathrm{~b}$.

Dong, D., P. Fang, Y. Bock, M. K. Cheng, and S. Miyazaki, Anatomy of apparent seasonal variations from GPS-derived site position time series, J. Geophys. Res., 107(B4), 2075, 9-1 to 9-16, 2002.

Ernst, W. G., R. Cao, and J. Jiang, Reconnaissance study of Precambrian metamorphic rocks, northwestern Sino-Korean shield, Peoples republic of China, Bull. Geol. Soc. Am., 100, 692-701, 1988.

Hamdy, A. M. and B.-G. Jo, Proposed program for monitoring recent Crustal movement in Korean Peninsula, Journal of Korean Geophysical Society, 5, 4, 283-292, 2002.
Hamdy, A. M., P.-H. Park, and B.-G. Jo, Preliminary crustal movement study around the Honam shear zone and Okchon Belt (South Korea) using GPS observation, Geosci. J., 8, 109-112, 2004a.

Hamdy, A. M., P.-H. Park, H.-C. Lim, K.-D. Park, Present day relative displacement between the Jeju Island and the Korean peninsula as seen from GPS observation, Earth Planets Space, 56, 927-931, 2004b.

Hamdy, A. M., P.-H. Park, and H.-C. Lim, Horizontal deformation in South Korea from permanent GPS network data, 2000-2003, Earth Planets Space, 57, 77-82, 2005.

Hurley, P. M., H. W. Pinson, and J. H. Lee, Middle Precambrian and older apparent age values in the basement gneisses of South Korea and relations with Southern Japan, Bull. Geol. Soc. Am., 84, 2299-2304, 1973.

Kim, S. G. and K. S. Lee, Seismic risk map of Korea obtained by using South and North Korea Earthquake catalogues, J. Earthq. Eng. Soc. Korea, 4, 1, 13-34, 2000.

Kyung, B. D., Correlation of earthquake occurrence with topography and lineaments in South Korea, J. Kor. Earth Sci. Soc., 14, 482-491, 1993.

Mäkinen, J., H. Koivula, M. Poutanen, and V. Saaranen, Vertical velocities in Finland from GPS networks and from repeated precise leveling, $J$. Geodyn., 35, 443-456, 2003.

Park, P.-H., U. Chwae, Y.-W. Han, and H. Choi, Preliminary GPS results and a possible neotectonic interpretation for South Korea, Earth Planets Space, 53, 937-941, 2001.

Reedman, A. J. and S. H. Um, Geology of Korea. Korean Institute of Energy resource, Seoul, Korea, 1975.

A. M. Hamdy (e-mail: amhamdy_eg@yahoo.com), P.-H. Park, and B. G. Jo 